D.O.I: $10.3895 /$ gi.v10i1.1514

\title{
EFICIÊNCIA ENERGÉTICA: O COMPORTAMENTO DOS DISCENTES DA UNIVERSIDADE ESTADUAL DA PARAÍBA EM RELAÇÃO AO CONSUMO RACIONAL DE ENERGIA ELÉTRICA
}

\section{ENERGY EFFICIENCY: THE BEHAVIOR OF LEARNERS STATE UNIVERSITY OF PARAÍBA IN RELATION TO THE RATIONAL CONSUMPTION OF ELECTRICITY}

\author{
Vamberto Oliveira de Souza ${ }^{1}$; Rosiclecia Camilla Oliveira do Amaral2; Carlos Cesar de Oliveira \\ Lacerda $^{3}$; Melline Enéas da Silva ${ }^{4}$; Sandra Maria Araújo de Souza ${ }^{5}$ \\ ${ }^{1}$ Universidade Estadual da Paraíba - UEPB - Campina Grande - Brasil \\ vamberto_@live.com \\ ${ }^{2}$ Universidade Estadual da Paraíba - UEPB - Campina Grande - Brasil \\ rosiclecia-91@ hotmail.com \\ ${ }^{3}$ Universidade Estadual da Paraíba - UEPB - Campina Grande - Brasil \\ cesarlacerda.adm@hotmail.com \\ ${ }^{4}$ Universidade Estadual da Paraíba - UEPB - Campina Grande - Brasil \\ mellineneasilva@hotmail.com \\ ${ }^{5}$ Universidade Estadual da Paraíba - UEPB - Campina Grande - Brasil \\ sandra.adm@hotmail.com
}

\begin{abstract}
Resumo
$O$ objetivo foi identificar o comportamento dos discentes da UEPB em relação ao consumo racional de energia elétrica. Para isso, utilizou-se a tipologia da pesquisa exploratória descritiva, onde foi utilizado como técnica e instrumento de pesquisa, com base no estudo de Camargo (2006), um questionário composto por questões fechadas. Nesta perspectiva, foi possivel perceber que os discentes da instituição em estudo, possuem um bom comportamento a cerca do tema sobre eficiência energética, ou seja, eles reconhecem que essas medidas são importantes para preservação das gerações futuras. No entanto, muitos destes alunos demonstraram um comportamento de não interesse ou não preocupação em utilizar essas informações no seu dia-adia. Espera-se que os resultados obtidos nesse trabalho forneçam os subsídios necessários para a realização do diagnóstico e a implementação das medidas necessárias para a eficiência energética, e consequentemente o desenvolvimento sustentável.
\end{abstract}

Palavras-chave: eficiência energética; consumo consciente; desenvolvimento sustentável.

\section{Introdução}

A evolução do homem sempre foi marcada pela exploração dos recursos que o planeta oferece: humanos e naturais. Tal exploração, diante da atual crise energética mundial, tem feito o termo eficiência energética ser amplamente divulgado, seja no âmbito acadêmico ou industrial (GOLDEMBERG, 2000). E nos últimos tempos a população vem acompanhando a exaustão das 
reservas naturais para uma maior obtenção de energia elétrica, ocasionando problemas em níveis mundiais, como a crise do petróleo de 1970 e, em nível nacional, como o "apagão" em 2001. Segundo Lamberts (1997, p. 14), "a eficiência energética pode ser entendida como a obtenção de um serviço com baixo dispêndio de energia”. O que denota que eficiência energética não está relacionada apenas com a redução do consumo de energia, mas também com a obtenção de um sistema eficiente do ponto de vista quantitativo e qualitativo, onde essa economia de energia representa a redução de investimentos em novas usinas e linhas de transmissão, com a consequente preservação do meio ambiente e redução no valor da tarifa, contribuindo assim, para o Desenvolvimento Sustentável.

Todavia, para alcançar o Desenvolvimento Sustentável é necessária uma mudança no padrão de produção e de consumo, e isto só é possível com um nível alto e acessível de informação, consciência e sensibilidade da população. Assim, é nesse contexto que se percebe a universidade como meio formador e multiplicador de informações e saberes, onde tem o dever de expandir uma conscientização dos recursos naturais através de uma educação voltada para o desenvolvimento e não para o crescimento humano.

Nesta perspectiva, há uma ampla discursão quanto à importância da Propagação da Eficiência Energética na sociedade, através de mudanças culturais, Salum (2002), onde tais mudanças podem representar significativa redução nos custos de energia elétrica. Desse modo, a inquietação da pesquisa se pauta no seguinte problema: Qual o comportamento dos discentes da Universidade Estadual da Paraíba (UEPB) em relação à eficiência energética? Assim, o objetivo foi identificar o comportamento dos discentes da UEPB em relação ao consumo racional de energia elétrica. Portanto, a pesquisa justifica-se pela urgência que a questão do Desenvolvimento Sustentável vem despertando na sociedade, já que a crise ambiental que se observa não se encontra em caráter passageiro, mas em questões prioritárias para o futuro da humanidade.

\section{Pressupostos teóricos}

\subsection{Setor energético}

Como é de conhecimento global, energia é o ponto central para a sustentabilidade, visto que a humanidade vive atualmente em uma extrema dependência da presença da eletricidade ou de algum combustível. Todavia, o planeta já não suportar o ritmo de consumo e as exigências do modo de vida da população que o habita. Sendo assim, esta realidade enfrenta um grande desequilíbrio, onde podemos ver claramente a desigualdade social, os desastres ambientais e uma economia fragilizada pela falta de recursos naturais.

Entretanto, apesar desta dependência muitos cidadãos consomem desenfreadamente sem se preocupar com os seus impactos, por vezes confundindo "bem-estar" com necessidade. Logo o uso 
inconsciente dos recursos naturais e a poluição aumentam diariamente, fazendo-se necessário um desenvolvimento sustentável em todas as suas dimensões, que conforme Natasha C. Penatti define em sua contribuição ao projeto Pé na Água como sendo "saber usar os recursos naturais para satisfazer as nossas necessidades, sem comprometer as necessidades e aspirações das gerações futuras" (p. 1).

Todavia, para amenizar os problemas causados pelo estilo de vida da maioria da população é necessário a política dos três R's: Reduzir, Reutilizar e Reciclar. Nesta perspectiva, a gravidade dos impactos ambientais que a humanidade causa depende, principalmente, das fontes de energia que se escolhe para a geração de eletricidade, produção e consumo.

No caso do Brasil, segundo Tolmasquim (2012, p. 2) o setor energético tem feito seu "dever de casa", visto que é citado como referência internacional, sobretudo, "na renovabilidade de sua matriz tanto energética quanto de produção de energia elétrica”. Entretanto, conforme Camargo (1996, p. 2) há dificuldades para financiar novos empreendimentos neste setor, já que “(...) os crescentes movimentos sociais e ecológicos contra a construção de grandes obras de geração e transmissão de energia elétrica (...)" têm retardado tal desenvolvimento.

Por fim, fica claro que o Brasil tem trilhado novos caminhos na questão energética com o intuito de incorporar ao planejamento do setor elétrico a nova realidade social, econômica e política do país, principalmente na necessidade e na realidade de se buscar um uso mais eficiente da energia produzida. Assim, mesmo sendo um país considerado alto suficiente em energia sabe-se que tudo tem um prazo de validade, um término, e cabe à população usar os recursos que tem hoje pensando no amanha.

\subsection{Consumo consciente}

Atualmente a humanidade não se encontra em sintonia com as consequências de seus atos, e isto se deve pela falta de compreensão que os recursos naturais são finitos e/ou por acreditarem que o ser humano sempre achará uma solução através da tecnologia. Contudo, estes se esquecem de que para fazer novas tecnologias o cidadão utilizará dos recursos disponíveis na biodiversidade, por vezes já escassos. Assim, torna-se necessário uma conscientização, um “despertar” para a realidade, que todos deixam suas "pegadas" no planeta, porém é preciso que essas pegadas não afetem as futuras gerações.

Diante deste cenário, a sociedade deve ser melhor conscientizada, desde o âmbito pessoal ao profissional, uma vez que o mercado de trabalho atual exige, cada vez mais, profissionais capacitados em uma formação ambiental, onde conforme Portillho (2005, p. 4) "o meio ambiente deixou de ser relacionado apenas a uma questão de como usamos os recursos (os padrões), para também estar vinculado à preocupação com o quanto usamos (os níveis)”. Portanto, o tópico em 
estudo (setor energético e consumo consciente) deve galgar para a eficiência energética, pois o mesmo tornou-se um problema de acesso, distribuição e justiça.

Todavia, apesar de existiram programas para a conservação de energia, a sociedade não tem noção da importância que tais programas representam para o desenvolvimento nacional quando se coloca em contra partida a ideia de "bem-estar". Com isso, as pessoas, em especial as da classe C, têm consumido mais energia, mesmo que isso cause por vezes um aumento das despesas no final do mês (CHIARA, 2011). O que denota que mais uma vez o "EU" está antes da coletividade e/ou dos outros.

Nessa perspectiva, os consumidores ainda não identificam o potencial de economia na aquisição de equipamentos com tecnologias mais eficientes. O que denota que o consumo não é uma de suas preocupações na hora da compra, mas sim qualidade, marca e preço. Deste modo, um simples desligar de lâmpadas e televisores quando não utilizada é uma ação elementar para a conservação de energia, onde só esta atitude não é suficiente, embora seja um passo para o desenvolvimento do consumo consciente.

Por fim, pode-se observar que para solucionar o problema ocasionado por toda a sociedade deve-se ter uma união das três esferas (econômica, social e ambiental) rumo a uma conscientização de toda a população, sem exclusividade e individualidade, de que as ações causadas hoje podem provocar no amanha resultados indesejados. Por isso cabe a cada um ensinar as novas gerações através de práticas de modo a incentivar iniciativas de natureza educacional.

\subsection{Eficiência energética}

O Brasil possui uma matriz energética considerada dentre as mais limpas, porém hoje está sendo necessário buscar energia em locais cada vez mais remotos, precisamente onde a biodiversidade e diversidade cultural estão mais conservadas. É o que esta acontecendo na Amazônia, de um lugar dos últimos remanescentes de grandes volumes e quedas d'água a paredões de concreto para a geração de eletricidade por hidrelétricas.

Deste modo, um conceito em evolução desde 1960 é o de eficiência energética, onde atualmente, pode-se falar nela como parte da busca de maior eficiência de nossa sociedade no uso de recursos naturais, principalmente da energia. Entretanto, hoje se percebe que quando se refere à eficiência energética a sociedade acredita que tal medida é algo difícil de fazer, porém:

(...) quando cada cidadão é consciente dos resultados das ações que evitam o desperdício e promovem o uso racional e eficiente de energia, acaba por exercer também sua responsabilidade ao cobrar dos governos e dos atores da economia medidas que busquem maior austeridade, suficiência, justiça social e ambiental na produção e consumo da energia (ORTIZ apud REHDER, 2007, p. 1).

O que mostra que o uso racional dos recursos naturais e uma eficiência energética são essenciais para que as pessoas tenham uma vida melhor no futuro. Entretanto, para que se tenha tal 
futuro é necessária uma conscientização no presente para que só assim possa-se ter o tão sonhado “futuro promissor”. Sendo assim, para que se tenha um consumo sustentável doméstico mais rápido, torna-se viável uma melhor contextualização das temáticas atuais (aquecimento global, catástrofes naturais, entre outros) visando o lado econômico, como meio de sensibilizador da sociedade para aderirem o desenvolvimento sustentável.

Todavia, um desenvolvimento sustentável deve estar alicerçado no equilíbrio das três esferas: econômico, social e ambiental. Portanto, o problema do consumo da população pode ser resolvido por uma substituição dos produtos e bens consumidos por outros que sejam menos poluentes e mais eficientes; em uma conscientização do consumidor nas compras; e em políticas mais rigorosas com empresas que não respeitem as leis ambientais. Contudo, o que se observa é uma discussão retórica, onde seria a redução drástica do volume de bens e serviços consumidos a solução para este problema.

Nesta perspectiva, a conservação de energia passa por alguns níveis de intervenção para a eliminação de desperdícios e o aumento da eficiência das unidades consumidoras e geradoras. Assim reaproveitamento os recursos naturais, pela reciclagem e redução do conteúdo energéticos dos produtos e serviços, rediscutindo as relações centro/periferia, no que tange ao transporte e à localização de empresas produtoras e comerciais. A mudança dos padrões éticos e estéticos, a partir dos quais a sociedade poderia penalizar os produtos e serviços mais energointensivos em favor de sua cidadania (LA ROVERE, 1985 e DIAS, 1999 apud DIAS, MATTOS, BALESTIERI p. 3).

Por fim, a racionalização de energia se faz necessária devido a questões econômicas e sociais e, sobretudo ambientais, uma vez que já se nota um crescente número de anormalidades no ecossistema do planeta Terra. Portanto, desperdícios podem ser evitados e/ou reaproveitados. Sendo assim, a racionalização é algo indispensável para que as futuras gerações possam existir com o mesmo meio com o qual o ser humano de hoje existe. Contudo, sabe-se que isto é bem relativo, visto que não se pode saber o que as futuras gerações irão precisar, porém tem-se a certeza que se no futuro existirem as mesmas condições ambientes que hoje se têm, as futuras gerações terão meios de como sobressair e já terão um crescimento baseado e visando em um desenvolvimento sustentável.

\subsection{Consumo de eletricidade no Brasil}

Segundo Abreu (2010), o Brasil, por sua vez, apresentou uma diminuição no crescimennto do consumo de eletricidade, que foi mais acentuado entre as décadas de 1970 e 1980, saiu de um patamar de consumo de 5,39\% a.a. para o de 1,78\% a.a. Porém, a partir de 1990, voltou a crescer chegando ao patamar de 3,32\%. Na década de 1970 houve o chamado milagre econnômico, em que o PIB crescia aproximadamente $8,34 \%$ a.a. e o consumo de eletricidade foi de 5,39\%. No entanto, 
na década de 1980 o país entrou em recessão e o crescimento anual do PIB caiu para 1,57\%. Já na década de 1990 houve uma reação e o crescimento do PIB foi de 2,65\% a.a. e o consumo anual de eletricidade sobem para 3,32\%. Pode-se dizer que um dos motivos desse crescimeento foi à implantação do Plano Real, que teve como resultado a estabilização dos preços e da inflação, o que ocasionou o aumento do poder de ccompra do trabalhador, aliado à oferta de crédito com prazos estendidos ou facilitados. O Plano Real, ao disponibilizar financiamento em longo prazo para os bens de consumo duráveis, incentivou a compra de eletrodomésticos e outros, causando o aumento da demanda por energia elétrica em todo território nacional.

Houve também a introdução de termoelétricas a gás natural e carvão mineral na matriz energética brasileira. O gás natural, normalmente, é citado como uma fonte mais limpa do que os outros combustíveis fósseis, para produção de energia elétrica, porém, isso só é verdade com relação à emissão de $\mathrm{CO} 2$ e para comparação com países nos quais a energia elétrica é produzida por carvão.

Considerando um cenário de forte integração entre mercados, o setor elétrico brasileiro, normatizado e estabelecido da maneira como está, cujo ambiente regulado demonstra condições favoráveis paara seu desenvolvimento, desempenha papel de suma importância para o desenvolvimento da nação. É preciso, entretanto, que ocorra, por parte do Poder Público, a implantação de políticas públicas efetivas para o segmento, como o desenvolvimento de fontes de energia renováveis, a fim de garantir investimentos no País de maneira sustentável, permitindo, assim, dar condições ao crescimento da nação, de forma contínua.

\section{Aspectos metodológicos}

Buscando alcançar os objetivos propostos, utilizou-se a tipologia da pesquisa exploratória descritiva, numa abrangência restrita ao corpo discente do Centro de Ciências Sociais e Aplicadas (CCSA) da Universidade Estadual da Paraíba (UEPB), no qual foram selecionados alunos entre os cursos de Administração, Ciências Contábeis, Serviço Social e Comunicação Social. Sendo 35 alunos, o que caracteriza uma pesquisa não probabilística.

E tendo como finalidade obter informações para suporte e fundamentação ao estudo, bem como fornecer condições para inferir e formular conclusões, foi utilizado como técnica e instrumento de pesquisa, com base no estudo de Camargo (2006), um questionário composto por questões fechadas dividido em três blocos: Conhecimento geral do uso da energia elétrica; no ambiente de trabalho; e na minha residência para economizar energia.

Utilizou-se a escala itemizada de Likert de 1 a 5 pontos, onde 1 representa, Concordo Plenamente, 2 - Concordo parcialmente, 3 - Não concordou nem discordou, 4 - Discordo parcialmente e 5 - Discordo plenamente. A análise dos dados foi através da frequência relativa e 
absoluta. A metodologia aplicada está relacionada na busca de identificar o comportamento dos discentes da UEPB em relação ao consumo racional de energia elétrica, no sentido de facilitar, informar e educar o público-alvo na sensibilização e motivação para o consumo consciente e sustentável, de forma, a incorporar no seu cotidiano o hábito de consumo de forma sustentável.

\section{Análise dos resultados}

\subsection{Conhecimento geral sobre o uso da energia elétrica}

Ao analisar o Gráfico 1, constatou-se que $82 \%$ discordou parcialmente e $14 \%$ discordou plenamente sobre a afirmativa, demonstrando o conhecimento destes alunos em relação aos problemas energéticos; $4 \%$ concordou plenamente, comprovando que acreditam que a humanidade possui e/ou possuirá o poder de resolver todos os problemas do planeta.

Gráfico 1 - Não devemos nos preocupar com a possibilidade de faltar energia elétrica no futuro. Afinal a humanidade sempre irá achar uma solução

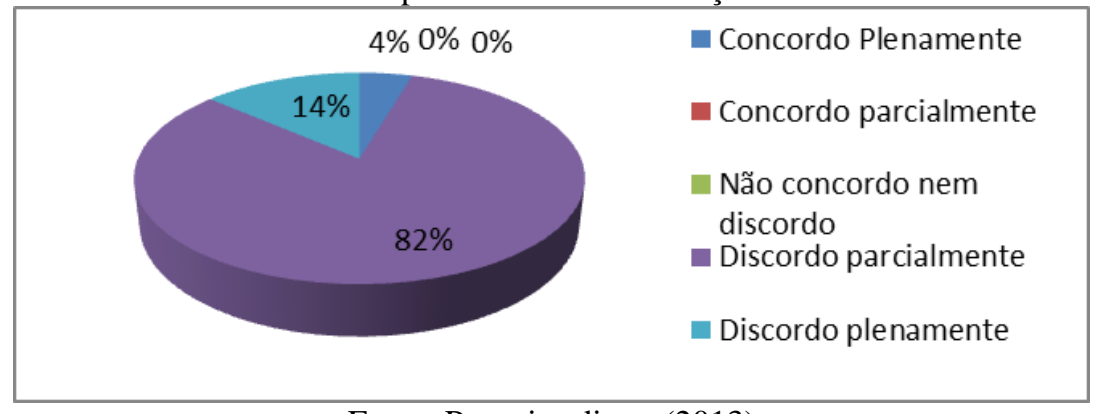

Fonte: Pesquisa direta (2013)

No Gráfico 2, observa-se que a maioria dos alunos (64\%) concordou parcialmente e 32\% concordam plenamente, o que denota entre estes que se todos os consumidores residenciais pouparem energia haverá alguma diferença positiva em relação ao consumo de energia, afirmando a importância do consumo consciente das residências e o impacto causado pelas mesmas como uma temática de relevância e preocupante para os entrevistados; $4 \%$ discordam parcialmente com a preposição, significando que estes acreditam que não é suficiente apenas as residências conservar energia.

Gráfico 2 - Se todos os consumidores residenciais conservarem energia haverá uma grande diferença no consumo de energia do Brasil

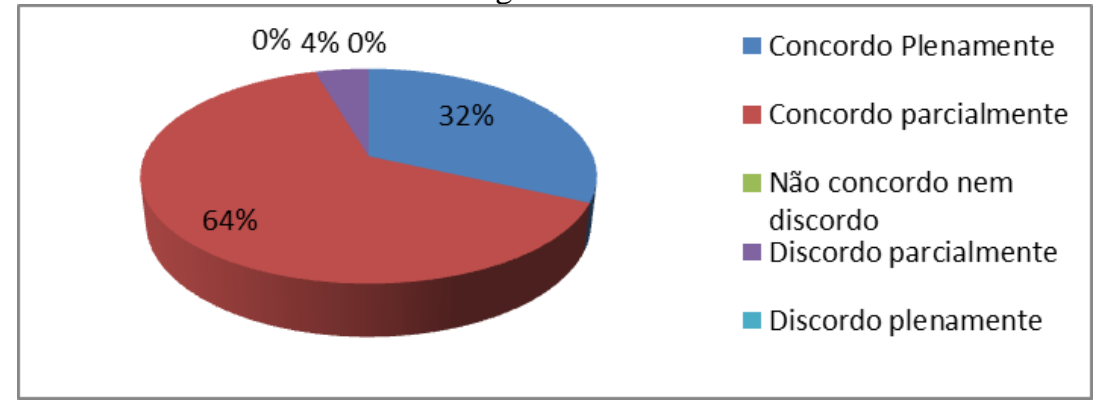

Fonte: Pesquisa direta (2013) 
Já no Gráfico 3, pode-se verificar que entre os entrevistados $41 \%$ discordam plenamente, $9 \%$ concordam parcialmente, $18 \%$ discordam parcialmente, $23 \%$ concordam plenamente e $9 \%$ não possui opinião quanto ao tema. Nesse aspecto, pode-se notar a grande fragmentação das respostas, o que denota um pensamento aberto quanto à temática, onde uns compreendem que a responsabilidade de construir usinas geradoras de energia elétrica é do governo, outros da iniciativa privada, e uma minoria como sendo uma junção das duas.

Gráfico 3 - A construção de novas usinas geradoras de energia elétrica deveria ficar a cargo da iniciativa privada

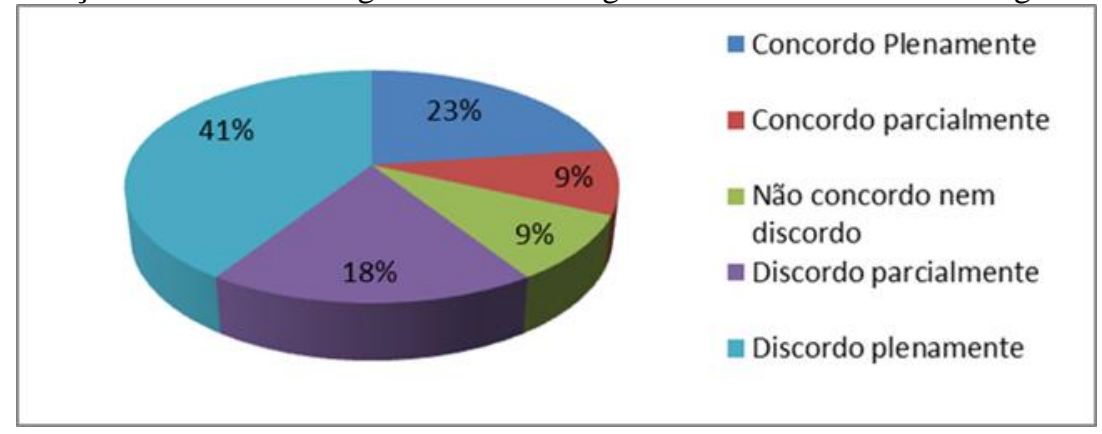

Fonte: Pesquisa direta (2013)

Seguindo as análises, no Gráfico 4, averiguou-se que a maior parte dos alunos $86 \%$ concordou parcialmente em relação à intervenção do governo, o que demonstra uma preocupação com o desenvolvimento social; $5 \%$ permaneceram neutros sobre tal questão; e $9 \%$ concordaram plenamente. Assim, de modo geral é de fácil compreensão que os entrevistados compreendam o papel do governo na execução de obras de bens públicos.

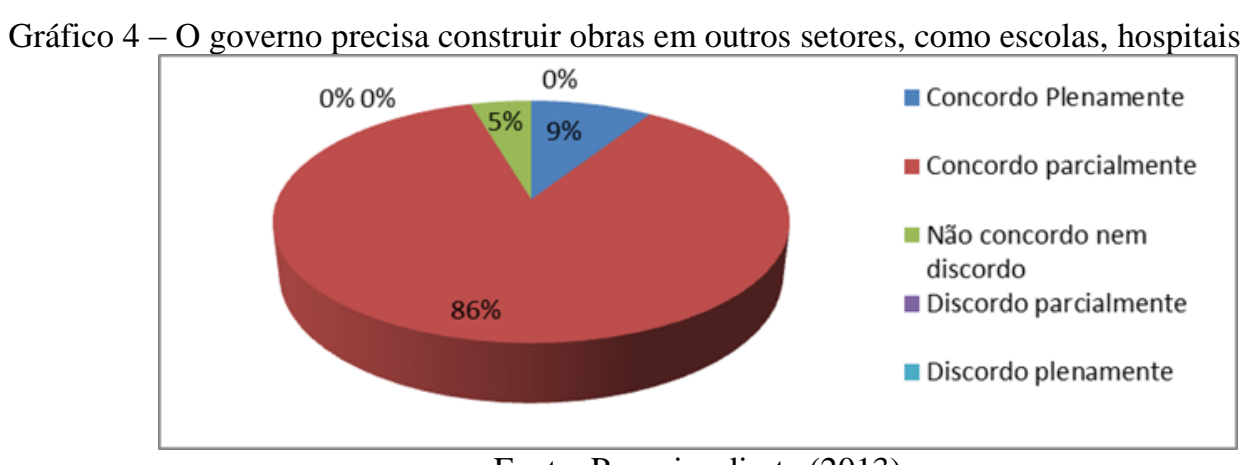

Fonte: Pesquisa direta (2013)

\subsection{No ambiente de trabalho}

Obtiveram-se no Gráfico 5 os seguintes dados: $50 \%$ dos entrevistados responderam "ás vezes" em relação a incentivar os colegas, 32\% responderam "sempre" sendo uma parte significativa, que se compromete em repassar informações sobre a importância de tal economia, e por fim 18\% afirmaram que "não" incentivam ninguém. Com isso, apesar da grande maioria incentivar as pessoas ao seu redor, a instituição deve trabalhar com palestras que repassem tal importância da economia elétrica de modo eficaz. 
Gráfico 5 - Incentiva os colegas a economizar energia

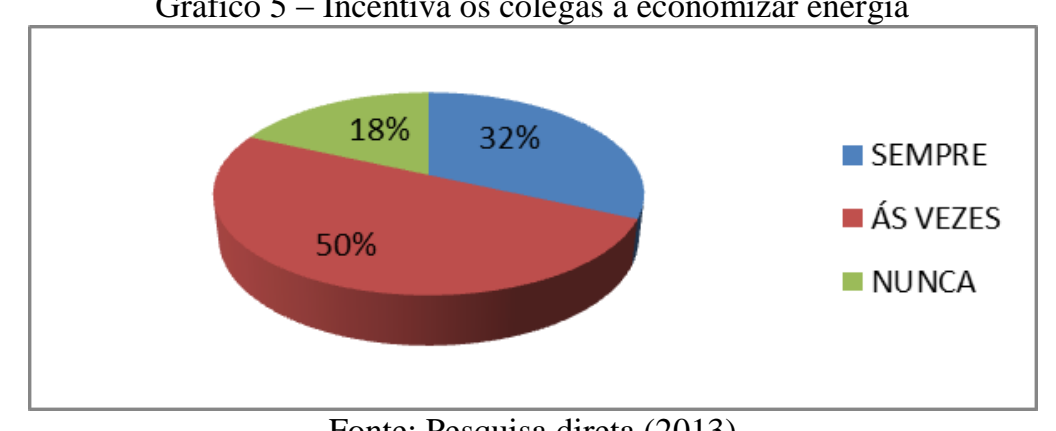

Fonte: Pesquisa direta (2013)

De acordo com o Gráfico 6, pode-se notar que a grande maioria dos alunos (86\%) se compromete em "sempre” apagar a luz da sala ao ser o último a sair, 9\% responderam "ás vezes" e 5\% "nunca" apagam. Todavia, apagar a luz de uma sala ao sair parece ser algo pequeno, porém é um ato que ajuda tanto na economia como no desperdício de energia quando se pensa no problema da falta de energia elétrica global. Assim, se todos os alunos da UEPB empenham-se em apagar as luzes nos setores que não possuem mais ninguém, isso geraria uma importante economia na instituição e ganhos financeiros e ambientais, beneficiando toda a sociedade e podendo ser um agente modificador da realidade.

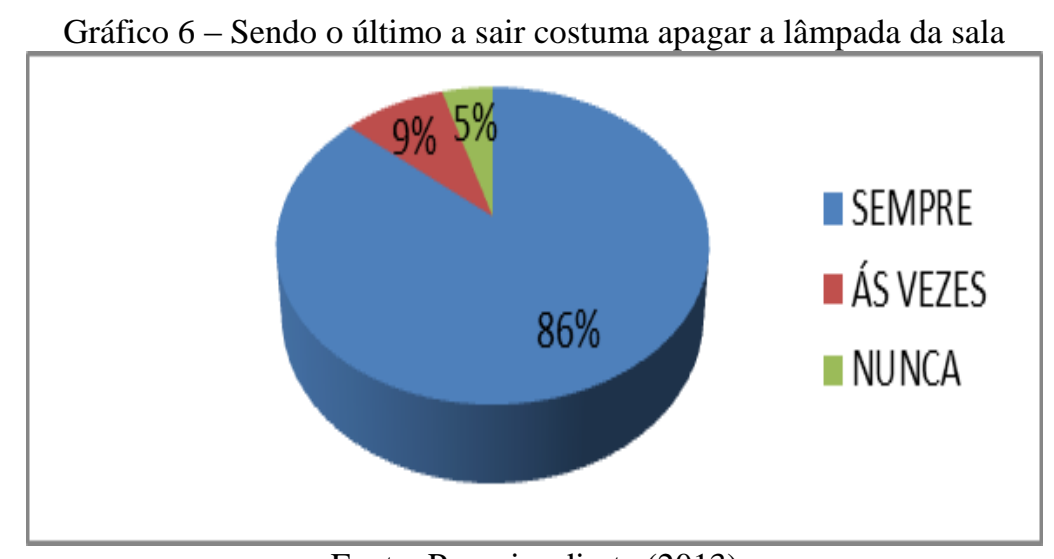

Fonte: Pesquisa direta (2013)

De forma complementar as análises realizadas, no Gráfico 7 observou-se que $50 \%$ dos alunos ao sair da sala desligam da tomada os equipamentos eletrônicos, $32 \%$ "nunca" desligam tais equipamentos e 18\% "ás vezes" desliga. Estes dados demonstram que ainda não é satisfatório o pensamento de eficiência energética entre os entrevistados, pois ainda não se obtém o pensamento conjunto em economizar energia elétrica. Desse modo, deve-se melhor trabalhar a consciência dos alunos quanto à afirmativa abordada. 
Gráfico 7 - Ao sair desligo da tomada os equipamentos eletrônicos da minha sala

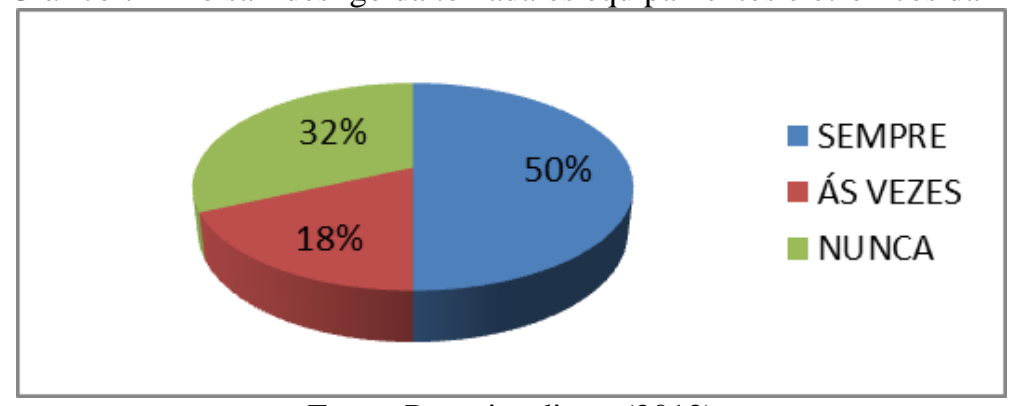

Fonte: Pesquisa direta (2013)

No Gráfico 8, constatou-se que o incentivo da universidade em campanhas para racionalizar a energia ainda não é satisfatório, pois $45 \%$ afirmaram que a universidade "nunca" incentivou a prática de racionar energia, 41\% responderam que "ás vezes" existem tais incentivos e 14\% alegaram que "sempre" existem tais campanhas. Assim, para mudar tal realidade é necessária a realização de projetos, palestras e minicursos dentro da própria universidade, como forma de disseminar e incentivar seus alunos na conscientização e importância em racionar energia elétrica.

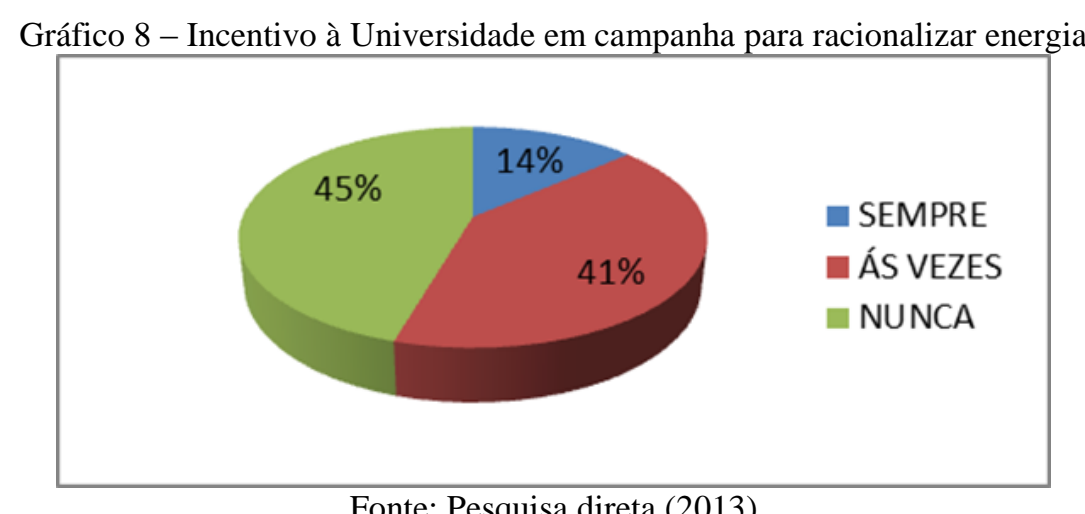

\subsection{Na minha residência para economizar energia}

Com base na análise do Gráfico 9, percebe-se que a grande maioria dos entrevistados (82\%) desligam "sempre" as lâmpadas quando não há necessidade de mantê-las acessas 14\% "ás vezes" e 4\% "nunca” desligam as lâmpadas. Logo, é compreensível a conscientização dos alunos referentes à economia de energia em relação a desligar as luzes, se preocupando com o desperdício de energia elétrica em suas casas. Esse tipo de preocupação é bem relevante, pois esse hábito gera economia na fatura de energia e ganhos ambientais, além da disseminação de conhecimento que os alunos repassam para os familiares, tornando assim um hábito familiar. 


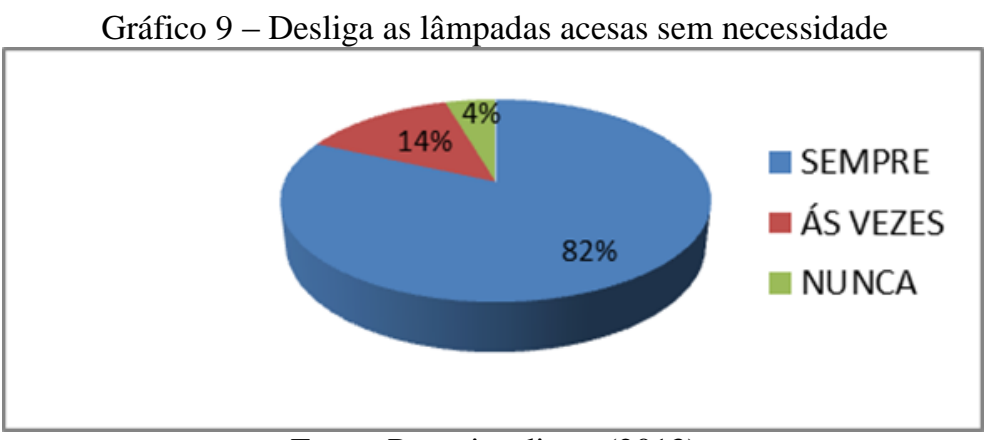

Fonte: Pesquisa direta (2013)

No Gráfico 10, verificou-se que boa parte dos alunos (64\%) desligam "sempre" os aparelhos de TV quando não há ninguém e (36\%) “ás vezes desligam”. A partir desses dados, conclui-se que os alunos possuem consciência e desligam os aparelhos, evitando desperdícios de energia, além desses pequenos hábitos refletirem também em relação a outros equipamentos eletrônicos que consomem energia elétrica.

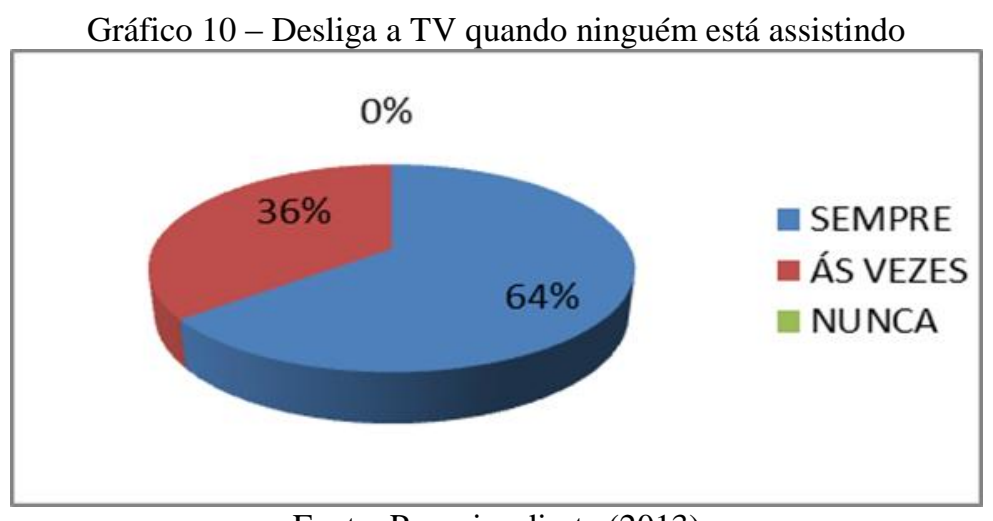

Fonte: Pesquisa direta (2013)

Na análise do Gráfico 11, observa-se que 50\% afirmaram que "ás vezes" diminui o tempo do banho para economizar energia, 41\% afirmaram "sempre" diminuir o tempo e 9\% "nunca" diminuem no pensamento de economizar. Portanto, questão do banho é preocupante, pois durante o banho muitas pessoas costumam deixar o chuveiro na mesma temperatura máxima e demorar muito, e o gasto de energia eleva-se. Assim, o governo federal tem investido em propagandas relacionadas à economia de água e energia no banho como forma de conscientizar a população, já que tal atitude reduz não só energia como também água, que hoje é tida como o maior meio de produção de energia no Brasil.

Gráfico 11 - Diminui o tempo de banho pensando em economizar energia

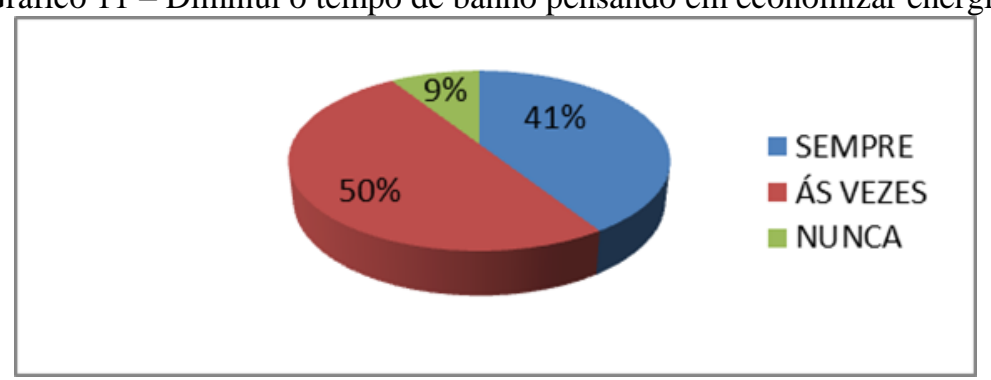

Fonte: Pesquisa direta (2013) 
E por último, na análise do Gráfico 12, observa-se que 68\% dos alunos da UEPB "sempre" desligam o ar condicionado quando saem do local com pensamento na racionalidade de energia elétrica, 23\% “ás vezes" e 9\% “nunca” possuem esse hábito. Logo, os alunos possuem uma consciência energética, onde se preocupam em economizar a energia desligando os equipamentos quando se ausentam, e apenas uma pequena parcela não possui tal hábito. O que denota a necessidade de mudanças de comportamento, com o intuito de reeducar as pessoas quanto à importância da economia e do uso racional de energia.

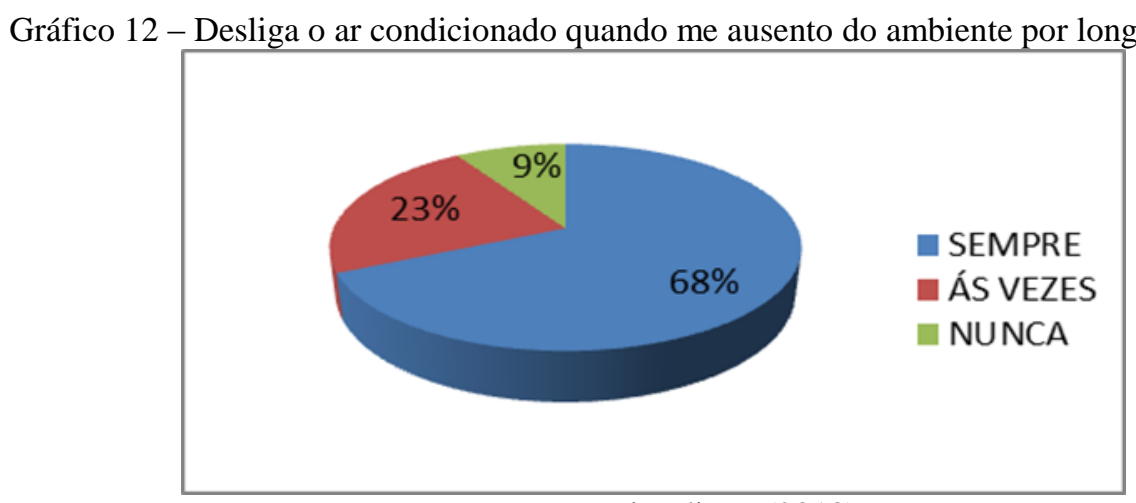

Fonte: Pesquisa direta (2013)

Nesta perspectiva, um dos assuntos mais falados nos últimos anos, sem dúvidas, é sobre o racionamento de energia, porém a sociedade sabe que economizar energia é uma atividade complicada, uma vez que os maus hábitos estão entrelaçados desde a infância e mudar isto é difícil. Para tanto, atualmente se torna necessário uma consciência no uso da energia elétrica para que se possa aproveitar a mesma sem racionamentos forçados pelo governo e sem danos à natureza.

\section{Considerações finais}

A busca pela eficiência energética trás vantagens para todos envolvidos, pois o usuário passa a gastar menos energia, além de contribuir com o meio ambiente em evitar o aumento do aquecimento global, as agressões ambientais decorrentes da construção de usinas hidrelétricas ou ao funcionamento de usinas termelétricas.

Percebe-se que conservar energia é manter ou melhorar o padrão de serviços e qualidade de vida, com menor custo no consumo. Com a redução ou eliminação dos desperdícios, a eficiência energética pode ser também interpretada como a maneira mais eficaz de usar a energia elétrica sem comprometer o conforto do ambiente de trabalho.

Com a pesquisa foi possível perceber que os discentes da Universidade Estadual da Paraíba possuem um bom comportamento a cerca do tema sobre eficiência energética, ou seja, eles reconhecem que essas medidas são importantes para preservação das gerações futuras. No entanto, muitos destes alunos demonstraram um comportamento de não interesse ou não preocupação em 
utilizar essas informações no seu dia-a-dia, isto é, o comportamento dos discentes ainda precisa ser trabalhado. Assim, os mesmos se mostraram durante a pesquisa que sabem da relevância da eficiência energética, porém em algumas questões ainda foram omissos com o compromisso do consumo consciente da energia para o desenvolvimento sustentável.

Nesta perspectiva, o trabalho recomenda sugestões e contribuições de como a Universidade Estadual da Paraíba pode estimular a prática entre os discentes. Através de métodos que mostrem a relevância do tema na área acadêmica, começando com a própria divulgação e incentivo do conceito na instituição, já que se percebe a falta de cursos e capacitação em prol da eficiência energética na universidade.

Dessa maneira, vão existir ganhos tanto econômicos, quanto ambientais, pois a eficiência energética faz com que as atividades sejam otimizadas através do uso das fontes de energia. Sendo assim, espera-se que os resultados obtidos nesse trabalho forneçam os subsídios necessários para a realização do diagnóstico e a implementação das medidas necessárias para a eficiência energética, e consequentemente o desenvolvimento sustentável.

\begin{abstract}
With the reduction or elimination of waste, energy efficiency can also be interpreted as the most effective way to use electricity. In this sense, the goal was to identify the behavior of students at UEPB over the rational consumption of electricity. For this, we used the typology of descriptive exploratory research, which was used as a technique and a research tool, based on the study of Camargo (2006), a questionnaire consisting of closed questions. In this perspective, it was revealed that students of the institution under study, have a good behavior around the theme of energy efficiency, ie, they recognize that these measures are important to preserve for future generations. However, many of these students demonstrated a behavior not interest or concern not to use this information in their day-to-day. It is expected that the results obtained in this work provide the necessary support for the diagnosis and implementation of measures for energy efficiency, and hence sustainable development.
\end{abstract}

Key-words: efficiency; conscious consumption; sustainable development; behavior.

\title{
Referências
}

ABREU Y.; OliVEIRA M. A.. G., GUERRA S. M. ; Energia sociedade e Meio Ambiente, Brasil 2010.

ALENCAR, L. H.; ALMEIDA, A. T.; MOTA, C. M. M. Sistemática proposta para seleção de fornecedores em gestão.

CAMARGO, C. C.. Gerenciamento pelo Lado da Demanda: Metodologia para Identificação do Potencial de Conservação de Energia Elétrica de Consumidores Residenciais. 1996. Tese (Doutorado em Engenharia de Produção) - Instituto de Engenharia de Produção, Universidade Federal de Santa Catarina, Florianópolis-SC. 1996. Disponível em: <http://www.eps.ufsc.br/teses96/camargo/index/index.htm>. Acessado em: 18 mar 2013.

CHIARA, M. D. Nova classe média já gasta mais com serviços do que com bens de consumo. 2011. O Estadão: Economia, Economia\&Negócios. Disponível em: <http://economia.estadao.com.br/noticias/economia, nova-classemedia-ja-gasta-mais-com-servicos-do-que-com-bens-de-consumo, 87493,0. htm>. Acessado em: 24 abr. 2013. 
DIAS, R. A.; MATTOS, C. R. D.; BALESTIERI, J. A. P. Conservação de energia: conceitos e sociedade. Núcleo de Estudos e Pesquisas em Educação Tecnológica. Centro Tecnológico - Universidade Federal de Santa Catarina.

Disponível em: <http://www.nepet.ufsc.br/Artigos/Texto/Cons_en.htm>. Acessado em: 20, março 2013.

GOLDEMBERG, J. Pesquisa e desenvolvimento na área de energia. São Paulo Perspect., vol., no. 3, 2000 , p.91-97.

LAMBERTS, R., et al. Eficiência energética na arquitetura. São Paulo: PW, 1997. 192p.

PENATTI, N. C. Consumo sustentável. Popularização da Ciência: Olhando para a Água, o projeto "Água e Cidadania na Bacia do Apa - uma Abordagem Sistemática e Trans-Fronteiriça na Década Brasileira da Água”. CTHIDRO/MCT/CNPq nº 15/2005. In: . SELEME, E.P.; ARNDT, E; SOUZA, P.R.; MEDEIROS, Y.; SANTOS,

M. Pé na Água: Uma abordagem transfronteiriça da Bacia do Apa. Campo Grande: Editora UFMS, 2008. CD-ROM. Disponível em: 〈http://www.planetaead.com.br/penaagua/apoio_didatico/artigos/ArtigoConsumoSustentavel.pdf>. Acessado em: 16 mar 2013.

PORTILHO, F. Consumo sustentável: limites e possibilidades de ambientalização e politização das práticas de consumo. Cadernos EBAPE.BR (ISSN: 1679-3951). Ideias, Debates e Inovações em Administração Contemporânea, v. 3, n. 3, 2005. Disponível em: < http://bibliotecadigital.fgv.br/ojs/index.php/cadernosebape/article/viewFile/4930/3664>. Acessado em: 17 mar 2013.

REHDER, L. ONGs lançam cartilha sobre uso sustentável de energia. UOL: Notícias, Ambiente, Tecnologias limpas e energias renováveis. 2007. Disponível em: <http://ecoviagem.uol.com.br/noticias/ambiente/tecnologiaslimpas-e-energias-renovaveis/ongs-lancam-cartilha-sobre-uso-sustentavel-de-energia-6728.asp>. Acessado em: 17 abr. 2013.

SALUM, L. J. B. Projeto Propagação da Eficiência Energética. Belo Horizonte: CEMIG, 2002.

TOLMASQUIM, M. T. Perspectivas e planejamento do setor energético no Brasil. Instituto de Estudos Avançados da Universidade de São Paulo. Estud. av. vol.26 no.74 São Paulo-SP, 2012. Disponível em:

<http://www.scielo.br/scielo.php?pid=S0103-40142012000100017\&script=sci_arttext>. Acessado em: 17 abr. 2013.

\section{Dados dos autores}

\section{Nome completo: Vamberto Oliveira de Souza}

Filiação institucional: Universidade Estadual da Paraíba - UEPB

Departamento: Departamento de Administração e Economia - DAEC

Função ou cargo ocupado: Graduando - Bolsista do PET - Administração

Endereço completo para correspondência: Rua Jovino Sobreira de Carvalho. Bairro: Jardim Paulistano - 1103 - Campina Grande, PB - Brasil, CEP: 58.415.305

Telefone: (83) 9650-6500

e-mail:vamberto_@live.com

\section{Nome completo: Rosiclecia Camilla Oliveira do Amaral}

Filiação institucional: Universidade Estadual da Paraíba - UEPB

Departamento: Departamento de Administração e Economia - DAEC

Função ou cargo ocupado: Graduanda - Bolsista do PET - Administração

Endereço completo para correspondência: Rua Baraúnas, bairro Universitário - 58429500 Campina Grande, PB - Brasil.

Telefone: (83) 33153300 
e-mail: rosiclecia-91@ @otmail.com

Nome completo: Carlos Cesar de Oliveira Lacerda

Filiação institucional: Universidade Estadual da Paraíba - UEPB

Departamento: Departamento de Administração e Economia - DAEC

Função ou cargo ocupado: Graduando - Bolsista do PET - Administração

Endereço completo para correspondência: Rua Baraúnas, bairro Universitário 58429500 - Campina

Grande, PB - Brasil

Telefone: (83) 33153300

e-mail: cesarlacerda.adm@hotmail.com

Nome completo: Melline Enéas da Silva

Filiação institucional: Universidade Estadual da Paraíba - UEPB

Departamento: Departamento de Administração e Economia - DAEC

Função ou cargo ocupado: Graduanda - Bolsista do PET - Administração

Endereço completo para correspondência: Rua Baraúnas, bairro Universitário 58429500 - Campina Grande, PB - Brasil.

Telefone: (83) 33153300

e-mail: mellineneasilva@ hotmail.com

Nome completo: Sandra Maria Araújo de Souza

Filiação institucional: Universidade Estadual da Paraíba - UEPB

Departamento: Departamento de Administração e Economia - DAEC

Função ou cargo ocupado: Profa. Doutora/ Orientadora - Depto. de Administração e Economia UEPB

Endereço completo para correspondência: Rua Baraúnas, bairro Universitário 58429500 - Campina Grande, PB - Brasil.

Telefone: (83) 33153300

e-mail: sandra.adm@hotmail.com

Submetido em: 04/05/2013

Aceito em: 07/10/2014 